\title{
Effects of bone anabolic agents on bone ultrastructure
}

\author{
B. Cortet
}

Published online: 29 May 2009

(C) International Osteoporosis Foundation and National Osteoporosis Foundation 2009

Erratum to: Osteoporosis International issue 198/20/6 DOI 10.1007/s00198-009-0862-9

The third sentence from the end of the section headed "Human data", in the right-hand column of page 1099, incorrectly stated: "In other words, the clearance rate of bone strontium appears to be low". The correct statement is: "In other words, the clearance rate of bone strontium appears to be high".

The online version of the original article can be found at http://dx.doi. org/10.1007/s00198-009-0862-9

B. Cortet $(\bowtie)$

Department of Rheumatology and EA 4032, CHU Lille,

59045 Lille, France

e-mail: bcortet@chru-lille.fr 